\title{
Effect of Nano Rubber Additions on Wear and Mechanical Properties of Epoxy Glass Fibre Composites
}

Srinivasarao $D^{1 *}$, Amareswari Reddy $\mathbf{M}^{1}$, Krishna Veni MNV ${ }^{1}$ and Sandeep Kumar Mahanti ${ }^{2}$

${ }^{1}$ Mechanical Engineering Department, ANITS, Visakhapatnam, India

${ }^{2}$ Mechanical Department, Grids Steel and Alloys, Cuttack, Odisha, India

\begin{abstract}
The use of polymer fiber reinforced composite materials is growing day by day in all types of engineering structures such as aerospace, automotive, aircraft, chemical, constructions etc. because of their tailorable properties. Through these materials are tailorable, improvement in tribological properties is demanded.
\end{abstract}

Keywords: Epoxy glass fiber composites; Nano nitrile butadiene rubber particles

\section{Introduction}

The word "COMPOSITE" in composite material signifies that two or more materials are combined on a microscopic scale to form a useful material. The advantage of composites is that they usually exhibit the best qualities of their constituent possesses [1]. Light, strong and corrosion-resistant, composite materials are being used. In an advanced society like ours we all depend on composite materials in some aspect of our lives. Fiber glass, developed in the late 1940's, was the first modern composite and is still the most common. It makes up about $65 \%$ of all the composites produced today and is used for boat hulls, surfboards, sporting goods, swimming pool linings, building panels and car bodies. For example, high-strength aluminum alloys do not resist corrosion but pure aluminum alloys are very corrosion resistant. Thus, a high strength aluminum alloy covered with a corrosion-resistant aluminum alloy is a composite material with unique and attractive advantages over its constituents.

\section{Classification of composites}

A composite is a material that consists of at least two distinct materials. Thus, numbers of composites are possible. For ease of recognition, they are classified based on two criteria [2].

- Based on type of matrix material as metal-matrix composites, polymer-Matrix composites and ceramic-matrix composites.

- Based on size-and-shape dispersed phase as particle-reinforced Composites, fiber- reinforced composites and structural composites.

\section{Fiber-Reinforced composite materials}

Fiber-reinforced composite materials consist of high strength and high modulus fibers in a matrix material. Reinforced steel bars embedded in concrete provide an example of fiber reinforced composites. Analysis of structural elements made of laminated composite materials involves several steps. As shown in Figure 1, the analysis requires knowledge of anisotropic elasticity, structural theories (i.e., kinematics of deformation) of laminates, analytical or computational methods to determine solutions of the governing equations, and failure theories to predict modes of failures and to determine failure loads.

\section{Laminates}

A laminate is a stack of laminate with various orientations of principal material directions in the laminate as in Figure 2. The layers of a laminate are usually bound together by the same matrix material that is used in the laminate.

Fabrication of thermosetting resin matrix composites: Initial form of constituent materials

Monomers or pre polymers of thermosetting resin systems are usually in a fluid state. They become solid as a result of a chemical reaction. During this chemical reaction, molecules of monomers or pre polymers are linked together to form polymer networks. This process of linking the molecules is called polymerization. The wet processes include hand lay-up molding, resin-transfer molding, filament winding, and pultrusion $[3,4]$.

\section{Hand lay-up technique}

The hand lay-up technique is the oldest, simplest, and most

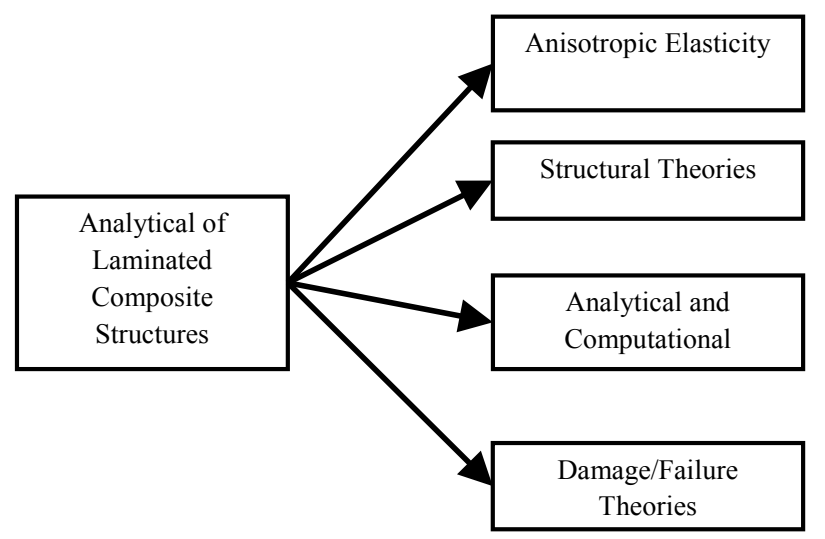

Figure 1: Basic analysis of laminated structures.

*Corresponding author: Srinivasarao D, Mechanical Engineering Department, ANITS, Visakhapatnam, India, Tel: 0891-254-3662; E-mail: dsr.cnu@gmail.com

Received May 05, 2014; Accepted October 27, 2014; Published November 02, 2014

Citation: Srinivasarao D, Amareswari Reddy M, Krishna Veni MNV, Sandeep Kumar M (2014) Effect of Nano Rubber Additions on Wear and Mechanical Properties of Epoxy Glass Fibre Composites. J Material Sci Eng 3: 143. doi:10.4172/21690022.1000143

Copyright: (C) 2014 Srinivasarao D, et al. This is an open-access article distributed under the terms of the Creative Commons Attribution License, which permits unrestricted use, distribution, and reproduction in any medium, provided the original author and source are credited. 

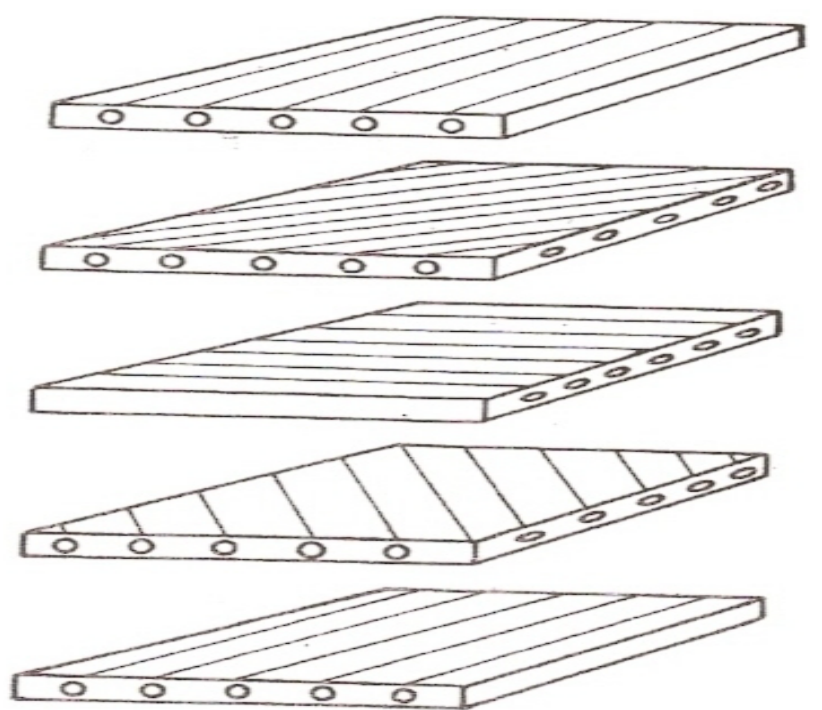

Figure 2: Laminate construction.

commonly used method for the manufacture of both small and large reinforced products. A flat surface, a cavity (female) or a positive (male) mold, made from wood, metal, plastics, reinforced plastics, or a combination of these materials may be used. Fiber reinforcements and resin are placed manually against the mold surface. Thickness is controlled by the layers of materials placed against the mold.

\section{Mold preparation}

Mold preparation requires a thorough machine buffing and polishing of the mold. After the desired finish has been attained, several coats (usually three or four) of paste wax are applied for the purpose of mold release. Many different release systems are available, such as wax, Poly Vinyl Alcohol (PVA), fluorocarbons, silicones, release papers and release films, and liquid internal releases.

\section{Gel coating}

Gel coating is normally a polyester, mineral-filled, pigmented, non reinforced layer or coating. It is applied first to the mold and thus becomes the outer surface of the laminate when complete.

\section{Hand lay-up}

In hand lay-up, the fiberglass is applied in the form of chopped strand mat, cloth, or woven roving. Premeasured resin and catalyst (hardener) are then thoroughly mixed together. The resin mixture can be applied to the glass either outside of or on the mold. To ensure complete air removal and wet-out, serrated rollers are used to compact the material against the mold to remove any entrapped air.

\section{Spray-up}

After the resin and glass mix is deposited, it is rolled by hand to remove air, to compact the fibers, and to smooth the surface.

\section{Bag molding processes}

Bag molding is one of the oldest and most versatile of the processes used in manufacturing composite parts. The laminate (pre impregnated or freshly impregnated with wet resin) are laid up in a mold, covered with a flexible diaphragm or bag, and cured with heat and pressure.

\section{Resin transfer molding}

Resin Transfer Molding (RTM) is a wet impregnation process in which fibers and resin are introduced separately into the mold. It requires placing dry-fiber reinforcement in the mold and introducing liquid resin in the closed mold to impregnate in the fibers and fill the mold cavity. RTM uses a mold with inlets for resins and outlets for air to escape.

\section{Filament winding}

Filament winding is a technique used for the manufacture of surfaces of revolution such as pipes, tubes, cylinders, and spheres and is used frequently for the construction of large tanks and pipe work for the chemical industry.

\section{Toughness in polymers}

The mechanical properties of materials are of great importance in engineering applications. An example of a stress-strain curve for a uniaxial tension experiment is shown in Figure 3a. The deformation is reversed upon removal of the applied stress up to the yield point, beyond which permanent (plastic) deformation occurs. Strain hardening occurs as the ultimate elongation is approached. Fracture occurs when the ultimate elongation is reached. Stress-strain curves often do not show some of the features depicted in Figure 3a. For example, for a very brittle material shown in Figure $3 b$, they typically end abruptly in fracture after a small amount of linear elastic deformation. Many different testing modes can be used to measure the mechanical properties of polymers. Uniaxial tension, uniaxial compression, plane strain compression, and simple shear, are among the most important testing modes, the specimen whose stress-strain behavior is shown in Figure $3 \mathrm{a}$ is 'tougher' than the specimen whose behavior is shown in Figure $3 \mathrm{~b}$. The material under a precisely defined set of test conditions.

\section{Rubber tear}

A mechanism devoted solely to the deformation and tearing to the rubber particles present in a two-phase system was proposed initially by Merz, Claver and Baer [5]. Its main proposal was that rubber particles quite simply hold the opposite faces of a propagating crack together. In the case of rubber modified epoxies, clear evidence of

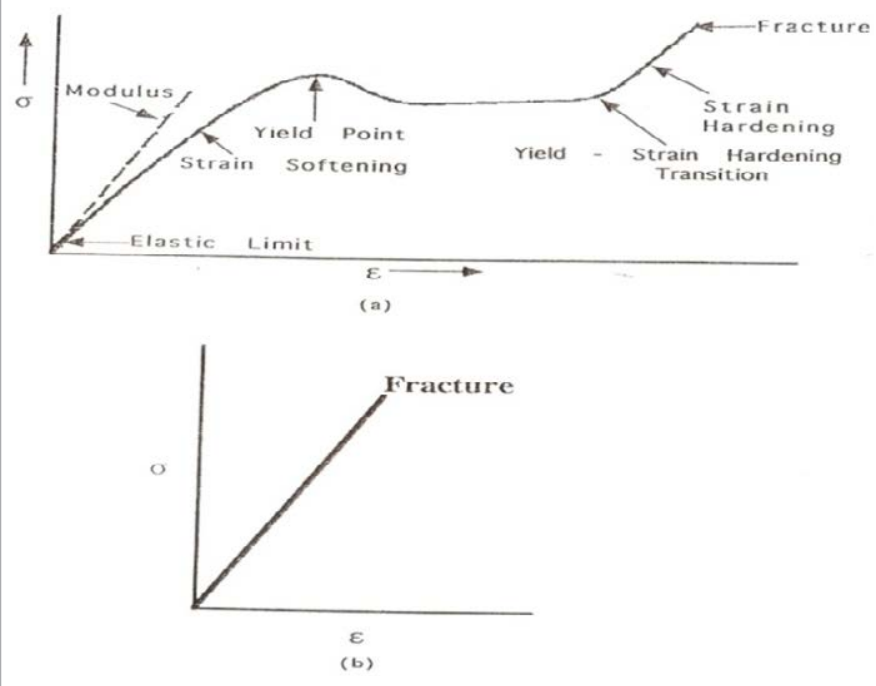

Figure 3: (a) General shape of the stress-strain curve (b) Shape of a stressstrain curve of a very brittle material. 
stretched rubber particles spanning loaded cracks. Indeed from such observations, Kunz-Douglas, Beaumont and Ashby proposed that the toughness enhancement provided by rubber particle incorporation was dependent primarily on the degree of elastic energy stored in the rubber particles during loading of the two-phase system. In addition they developed a quantitative model based on these proposals which is depicted mathematically thus:

$$
\mathrm{G}_{\mathrm{Ic}}=\mathrm{G}_{\text {Ice }}\left(1-\mathrm{V}_{\mathrm{p}}\right)+\left(1-6 / \lambda_{\mathrm{t}}^{2}+\lambda_{\mathrm{t}}+4\right) 4 \gamma_{\mathrm{t}} \mathrm{V}_{\mathrm{p}}
$$

Where $V_{p}$ is the volume fraction of the rubber particles, $\gamma_{t}$ is the particle tear energy, $\lambda_{t}$ is the rubber particle extension ratio at failure and $G_{\text {Ice }}$ is the fracture energy of the epoxy matrix.

\section{Multiple crazing}

The multiple crazing theories are due to Bucknall and Smith [6]; propose that toughness enhancement is attributed to the generation and efficient termination of crazes by rubber particles. Sultan and McGarry in their early work proposed that their improvements in toughness were due to the generation of crazes in the vicinity of rubber particles in an identical manner to that found in modified thermoplastics. In addition the frequently observed stress whitening phenomenon was attributed to the generation of crazes.More recently the possibility of crazing as a toughening mechanism in rubber modified epoxies has been suggested by Bucknall and Yoshii [7] in addition to shear deformation.

\section{Shear yielding}

This theory was proposed by Newman and Strella [8] following work on acrylonitrile-butadiene-styrene thermoplastics. Its main proposal is that shear deformation, occurring either as shear bands or as a more diffuse form of shear yielding.Possibly the greatest difficulty with this mechanism has concerned its inability to account for stress whitening, owing to shear yielding being a constant volume deformation process. Indeed, as previously described, a combined mechanism of this type has been proposed as the major source of toughness enhancement in rubber modified epoxies by Sultan and McGarry.

\section{Cavitation-shear yielding}

A toughening mechanism developed and proposed independently by Kinloch, Shaw and Hunston and by Pearson and Yee [9] is now generally recognized as the most consistent in terms of the experimental data and observations generated in recent years.

Goodier first considered this effect in 1933by studying the case of an isolated spherical particle embedded in an isotropic elastic matrix which is subjected to a uniform uniaxial tensile stress remote from the particle.

\section{Wear}

Wear is erosion or sideways displacement of material from its "derivative" and original position on a solid surface performed by the action of another surface. The definition of wear may include loss of dimension from plastic deformation if it's originated at the interface between two sliding surfaces. Cavitation wear is a form of wear where the erosive medium or counter-body is a fluid.

\section{Measurement}

The ASTM International Committee G-2 attempts to standardize wear testing for specific applications, which are periodically updated. The Society for Tribology and Lubrication Engineers (STLE) has documented a large number of frictional wear and lubrication tests.

\section{Types of wear}

Adhesive wear, Abrasive wear, Surface fatigue, Fretting wear, Erosive wear

\section{Materials and Methods}

\section{Materials epoxy resin system}

Epoxy resin systems are made up of an epoxy resin and a curing agent (also called a hardener or catalyst). Many epoxy products also contain additives such as organic solvents, fillers such as fiberglass or sand, and pigments.

\section{Epoxy resin properties (araldite ly 556)}

Chemical name: Bisphenol of diglycidyl ether

Viscosity

- 1350-2000 mpa*s

Specific gravity

$-1.1-1.2 \mathrm{~g} / \mathrm{cm}^{3}$

Epoxy content

- $4.20-4.35 \mathrm{eq} / \mathrm{kg}$

Appearance

- Clear liquid

Flash point

$-160^{\circ} \mathrm{C}$

Epoxy hardener properties (araldite hy 951)

$\begin{array}{ll}\text { Viscosity } & -10-20 \mathrm{mpa}^{*} \mathrm{~s} \\ \text { Specific gravity } & -0.98 \mathrm{~g} / \mathrm{cm}^{3} \\ \text { Appearance } & - \text { Clear liquid } \\ \text { Flash point } & -110^{\circ} \mathrm{C}\end{array}$

Glass fibre: Over $95 \%$ of the fibers used in reinforced plastics are glass fibers, as they are inexpensive, easy to manufacture and possess high strength and stiffness with respect to the plastics with which they are reinforced [10]. Addition of chemicals to silica sand while making glass yields different types of glasses. E-Glass has been used extensively in polymer matrix composites, commonly termed "fibreglass".

Fibre manufacture: Glass fibres are generally produced using melt spinning techniques. These involve melting the glass composition into a platinum crown which has small holes for the molten glass to flow. Continuous fibres can be drawn out through the holes and wound onto spindles, while short fibres may be produced by spinning the crown, which forces molten glass out through the holes centrifugally. Fibres are cut to length using mechanical means or air jets. As fibres are being produced, they are normally treated with sizing and coupling agents. These reduce the effects of fibre-fibre abrasion which can significantly degrade the mechanical strength of the individual fibres. Other treatments may also be used to promote wetting and adherence of the matrix material to the fibre.

Composition: S-Glass has a typical nominal composition of $\mathrm{SiO}_{2}$ $65 \mathrm{wt} \%, \mathrm{Al}_{2} \mathrm{O}_{3} 25 \mathrm{wt} \%, \mathrm{MgO} 10 \mathrm{wt} \%$. Some other materials may also be present at impurity levels (Table 1 and Figure 4).

\section{Key properties}

Nitrile butadiene rubber: Nitrile rubber, also known as Buna- $\mathrm{N}$, Perbunan, or NBR, is a synthetic rubber copolymer of acrylonitrile (ACN) and butadiene. Trade names include Nipol, Krynac and Europrene. Nitrile butadiene rubber (NBR) is a family of unsaturated copolymers of 2-propenenitrile and various butadiene monomers (1, 2-butadiene and 1,3-butadiene). Although its physical and chemical 
Citation: Srinivasarao D, Amareswari Reddy M, Krishna Veni MNV, Sandeep Kumar M (2014) Effect of Nano Rubber Additions on Wear and Mechanical Properties of Epoxy Glass Fibre Composites. J Material Sci Eng 3: 143. doi:10.4172/2169-0022.1000143

\begin{tabular}{|c|c|c|c|}
\hline Materials & Density (g/cm & $\begin{array}{c}\text { Tensile Strength } \\
\mathbf{( M P a )}\end{array}$ & Young modulus (GPa) \\
\hline E-Glass & 2.55 & 2000 & 80 \\
\hline S-Glass & 2.49 & 4750 & 89 \\
\hline Alumina (Saffil) & 3.28 & 1950 & 297 \\
\hline Carbon & 2.00 & 2900 & 525 \\
\hline Kevlar 29 & 1.44 & 2860 & 64 \\
\hline Kevlar 49 & 1.44 & 3750 & 136 \\
\hline
\end{tabular}

Table 1: Comparison of typical properties for some common fibres.

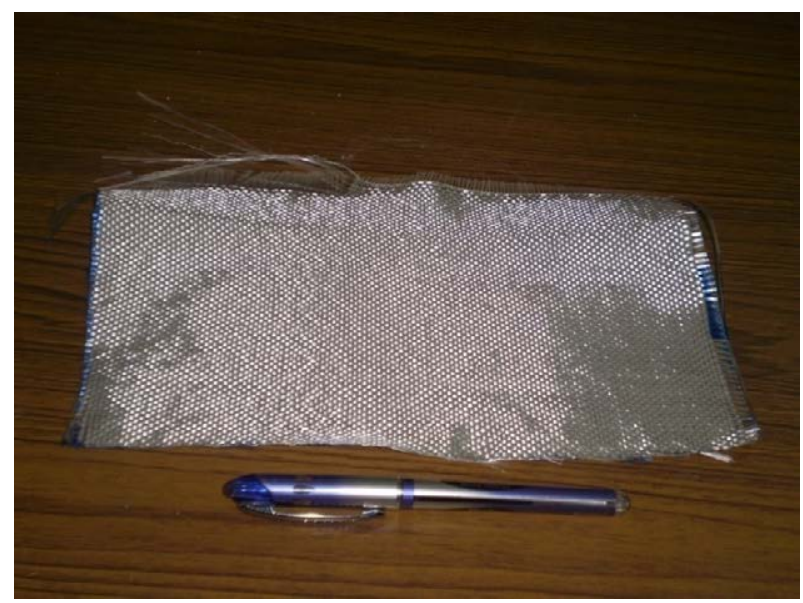

Figure 4: Bi directional s-glass woven fibre.

properties vary depending on the polymer's composition of nitrile, this form of synthetic rubber is generally resistant to oil, fuel, and other chemicals (the more nitrile within the polymer, the higher the resistance to oils but the lower the flexibility of the material).

\section{Mechanical properties}

Young's modulus

$-2-5 \mathrm{Mpa}$

Tensile strength

- 10-20 Mpa

Elongation

-200-500\% (Figure 5)

\section{Fabrication of composites}

Fabrication of dies: The below die is a stainless steel material of 316L grade type from Andhra steel pvt.ltd (Hyderabad) (Figure 6). The specification for the die and its corresponding frame are given as

Specification: 2 dies $200 \times 300 \times 4 \mathrm{~mm}$

1 die $190 \times 280 \times 4 \mathrm{~mm}$ (outer die size)

1 die $160 \times 250 \times 4$ (inner die size)

Fabrication of material: A glass fabric 5 mil mat and epoxy resin LY556 along with hardener HY951 are taken for the fabrication of the samples. The nominal content of glass fiber in the composite is set at $50 \%$ by weight and the remaining $50 \%$ has been allocated to the resin and hardener mixture. In that mixture, hardener is taken as $10 \%$ of the entire mixture. The thickness of each composite sample plate is $4 \mathrm{~mm}$ and $2 \mathrm{~mm}$.

Preparation of sample: Fabrication is the process adopted and employed for preparation of the composite sample plate for the performing the vibration test. The composite sample plates are fabricated in rectangular shape with the glass fiber fabric mats oriented at $0^{\circ}$ towards length and width directions. Hand Lay Up technique is the fabrication process used for the fabrication of the composite sample plate (Figure 7).

The technique, also called contact lay-up, as shown in Figure 3 is an open-mold method of molding thermosetting resins (polyesters and epoxies) in association with fibers (usually glass-fiber mat, fabric, or woven roving).

Hand lay-up technique: A total of 16 glass fibre cloths as per the specified dimension of $300 \mathrm{~mm} \mathrm{X} 180 \mathrm{~mm}$ of the final mold are arranged. Over the gel coat, glass fabric mat which has been cut according to required specification has been positioned in the open mold properly and then the resin solution containing the rubber particles is poured on it. Entrapped air below the first fiber layer can be removed either manually with squeegees or rollers. In the same manner

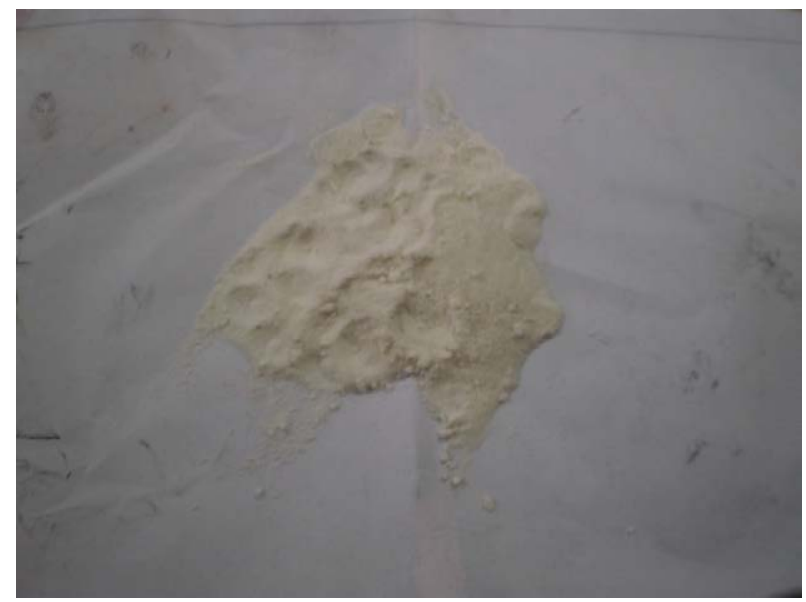

Figure 5: Acrylonitrile butadiene rubber
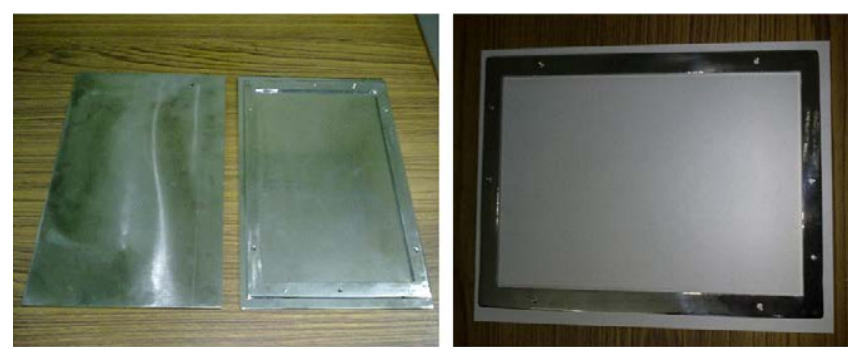

Figure 6: Dissembled dies.
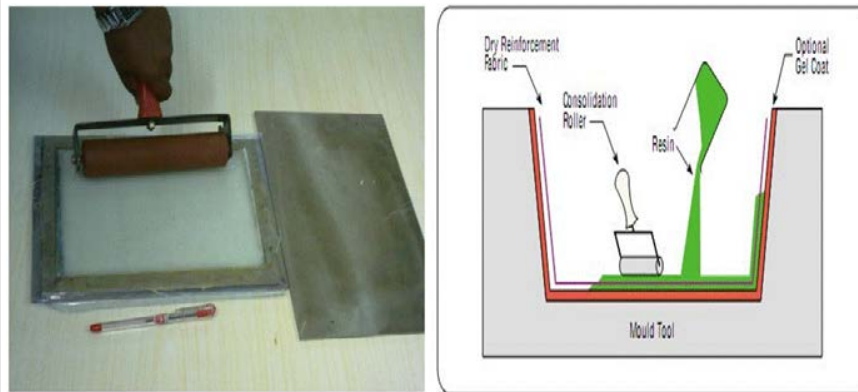

Figure 7: Hand Lay-up Technique. 
Citation: Srinivasarao D, Amareswari Reddy M, Krishna Veni MNV, Sandeep Kumar M (2014) Effect of Nano Rubber Additions on Wear and Mechanical Properties of Epoxy Glass Fibre Composites. J Material Sci Eng 3: 143. doi:10.4172/2169-0022.1000143

Page 5 of 8

all 16 fiber layers are positioned in the open mold one after another and the resin solution is poured and spread on each layer and cured at room temperature for 24 hours. The samples in the form of plates are cut of $300 \times 180 \times 4 \mathrm{~mm}$ (Figure 8 ).

Particle size analyzer: Particle size analyzer is used to characterize the size distribution of particles in a given sample. Particle size analysis can be applied to solid materials, suspensions, emulsions and even aerosols. There are many different methods employed to measure particle size (Figure 9).

Morphology studies of scanning electron microscope: The Scanning Electron Microscope (SEM) is a type of electron microscope that images the sample surface by scanning it with a high-energy beam of electrons in a raster scan pattern. The electrons interact with the atoms that make up the sample producing signals that contain information about the sample's surface topography, composition and other properties such as electrical conductivity (Figure 10).

Wear properties: A flat or a sphere shaped indenter is loaded on to the test sample with a precisely known force. The indenter(a pin or a ball) is mounted on a stiff lever, designed as a frictionless force transducer. As the disc is rotated, resulting frictional forces acting between the pin and the disk are measured by very small deflections of the armusing strain gauge sensor. Wear coefficients for both the pin and sample are calculated from the deterrmenation and study of friction and wear behaviour of almost every solid state material combination, with varying time, contact pressure, velocity, temperature, humidity, lubrication etc (Figure 11)

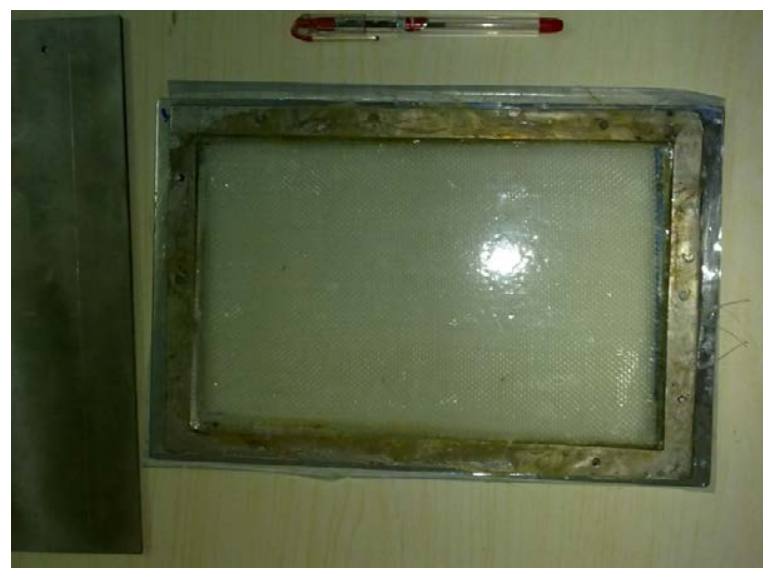

Figure 8: Photography of composite material.

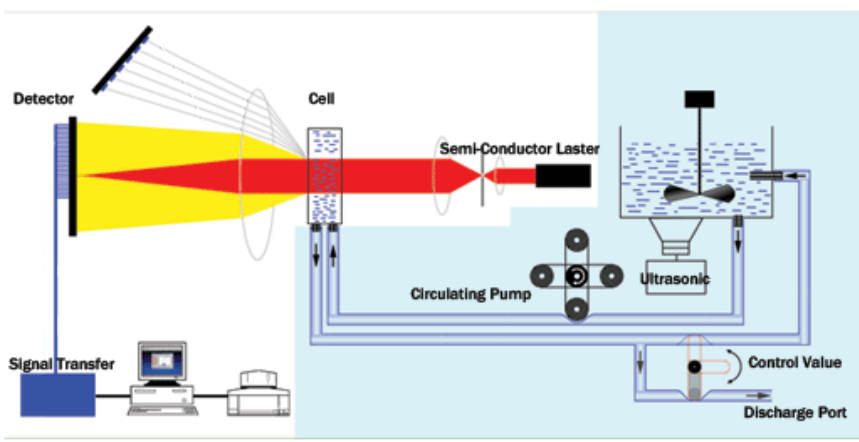

Figure 9: A Photo graph of particle size analyser
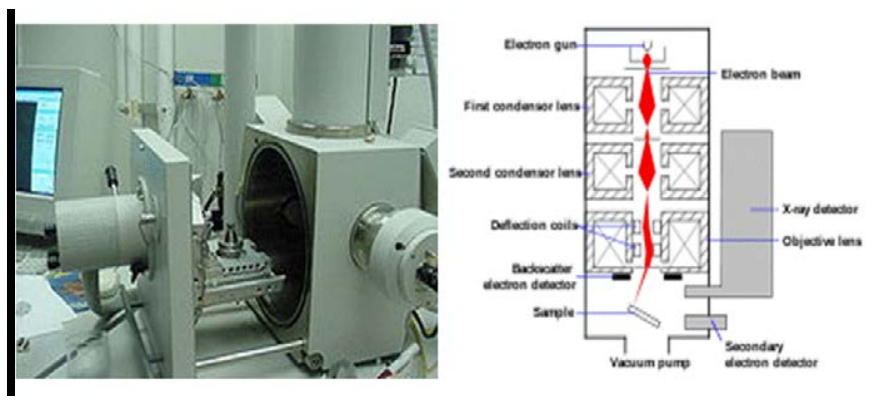

Figure 10: Photography of scanning electron microscope.

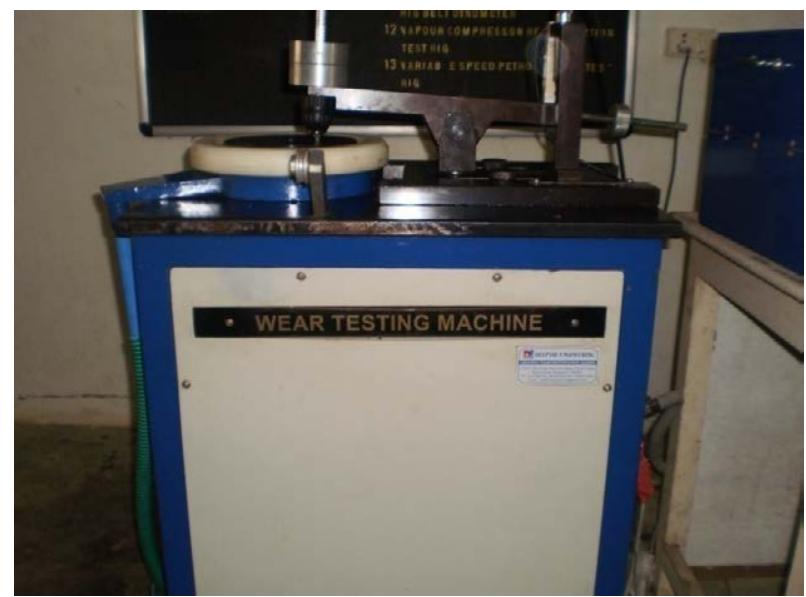

Figure 11: Photography of wear testing machine.

Tensile properties: Tensile properties indicate how the material will react to forces being applied in tension. A tensile test is a fundamental mechanical test where a carefully prepared specimen is loaded in a very controlled manner while measuring the applied load and the elongation of the specimen over some distance. The main product of a tensile test is a load versus elongation curve which is then converted into a stress versus strain curve. A typical engineering stressstrain curve is shown below. If the true stress, based on the actual crosssectional area of the specimen, is used, it is found that the stress-strain curve increases continuously up to fracture (Figure 12).

Flexure properties: The flexural test measures the force required to bend a beam under three point loading conditions. The data is often used to select materials for parts that will support loads without flexing (Figure 13).

Evaluation of weight fractions: Burn out test is carried out as per ASTM standards D618 to find the weight fractions of fibers and matrix present in composites. Three specimens are tested using electric muffle furnace. The specimens of size $20 \mathrm{~mm} \times 20 \mathrm{~mm}$ are considered for the test. The average fiber weight fraction is found as $40 \%$ of the total weight of the each sample (Figure 14).

\section{Results and Discussions}

\section{Morphology studies of particle size analyzer}

Morphology studies of scanning electron microscope: The morphology of the cross section of nitrile butadiene rubber filled 
Citation: Srinivasarao D, Amareswari Reddy M, Krishna Veni MNV, Sandeep Kumar M (2014) Effect of Nano Rubber Additions on Wear and Mechanical Properties of Epoxy Glass Fibre Composites. J Material Sci Eng 3: 143. doi:10.4172/2169-0022.1000143

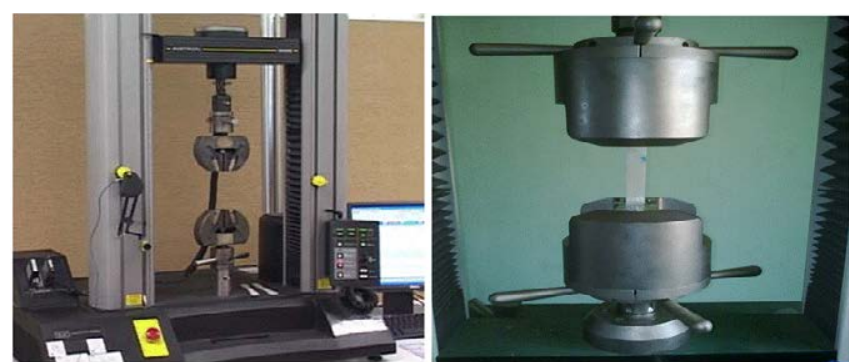

Figure 12: Universal Testing Machine for Tensile test.
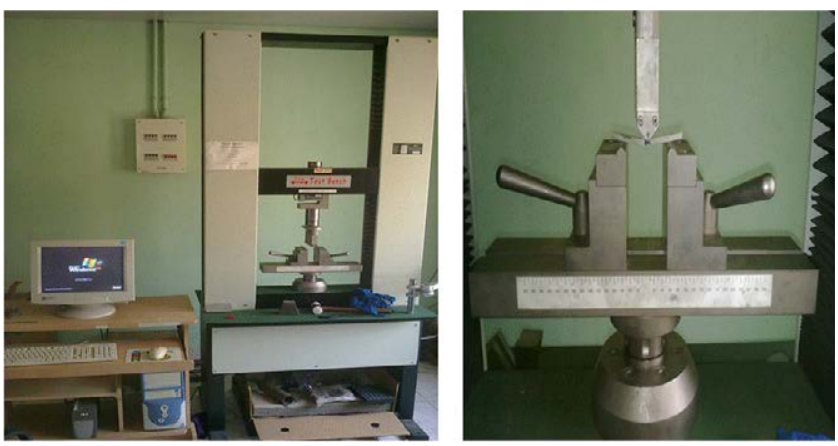

Figure 13: Universal Testing Machine for flexure test.
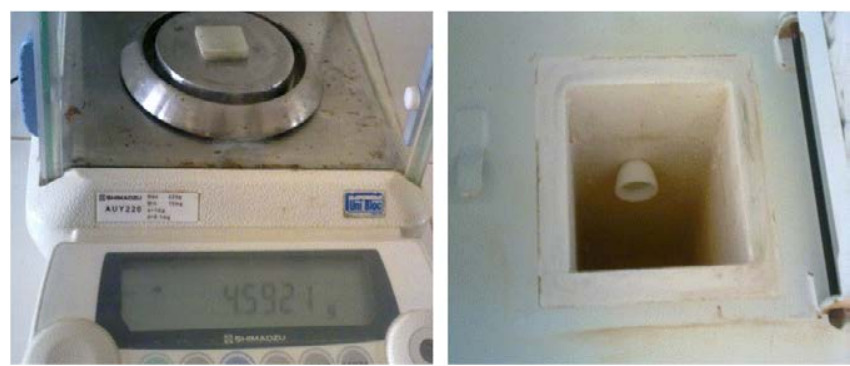

Figure 14: (a) Weight of the specimen (b) specimen in muffle furnace.

epoxy glass fiber composites were examined using Scanning Electron Microscopy (SEM), ZEISS $\mathrm{EVO}^{\circ} \mathrm{MA15}$, in order to examine distribution of rubber particles in the composite. Samples are coated with gold using plasma sputter apparatus. Morphology studies reveal the aspects of fiber bonding, adhesion between fiber and matrix and distribution of particle rubber in the glass epoxy composite [11]. SEM micrograph of the cut surface of glass fiber-reinforced epoxy resin composite specimen with rubber particles. It is reviled that rubber particles are well distributed in the matrix (Figures 15-17).

Wear properties: The variation of weight loss of composite specimens measured after specific time interval at each weight fraction of nano rubber is reported in figure. It is releaved that addition of nano rubber inclusions in composite increases the wear resistance and there by decreases the weight loss increases as time increases as usual. However the rate of increase of weight loss decreased with time among the selected particle inclusions (Figure 18).

Tensile strength properties: I observed from below graph that the strength increases with the increase of the \% of nano rubber in composite material. This is due to nano rubber having high young's modulus. Hence it is proved that as the \% of nano rubber increases. The strength also increases (Figure 19).

Tensile modulus properties: I observed from below graph that the stiffness decreases with the increase of the \% of nano rubber in composite material. This is due to nano rubber having high young's modulus. Hence it is proved that as the $\%$ of nano rubber increases. The stiffness decreases (Figure 20).

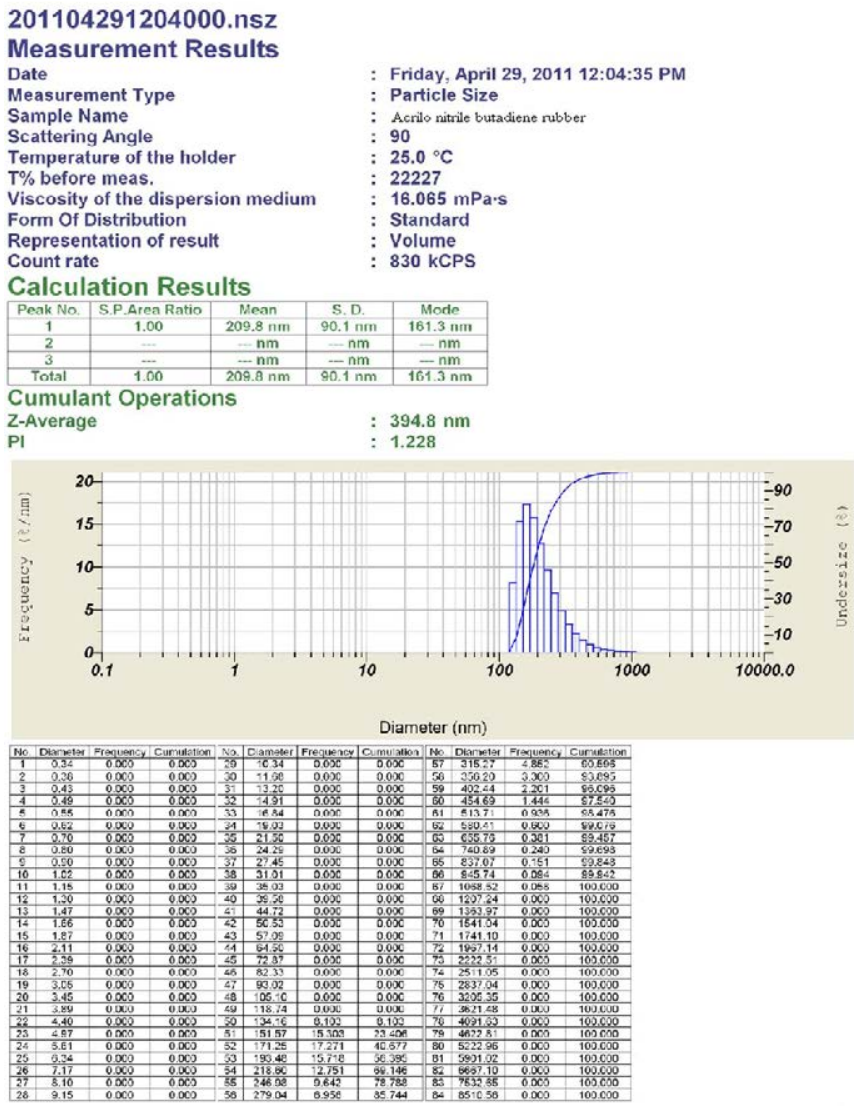

Figure 15: Morphology studies of particle size analyzer measurement results.

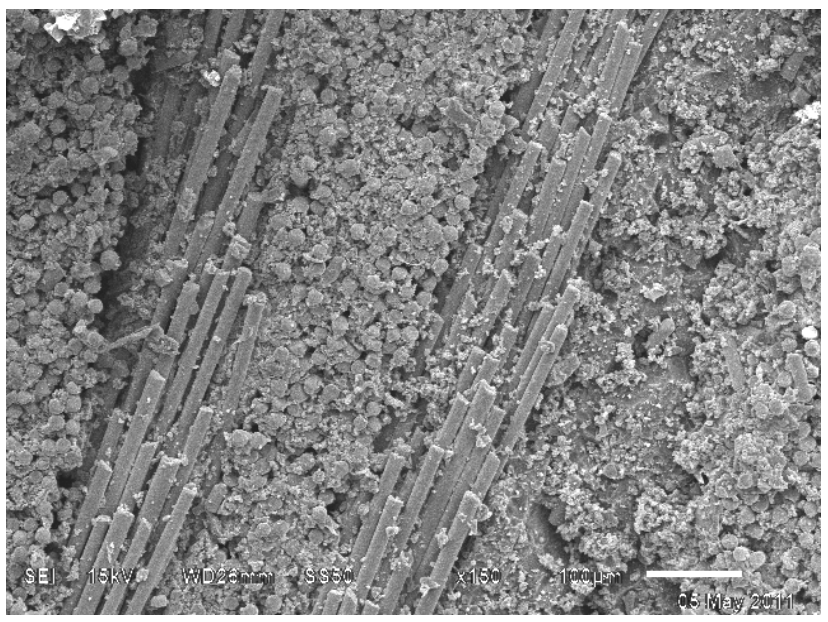

Figure 16: Nano rubber filled epoxy with glass fiber composite. 
Citation: Srinivasarao D, Amareswari Reddy M, Krishna Veni MNV, Sandeep Kumar M (2014) Effect of Nano Rubber Additions on Wear and Mechanical Properties of Epoxy Glass Fibre Composites. J Material Sci Eng 3: 143. doi:10.4172/2169-0022.1000143

Page 7 of 8

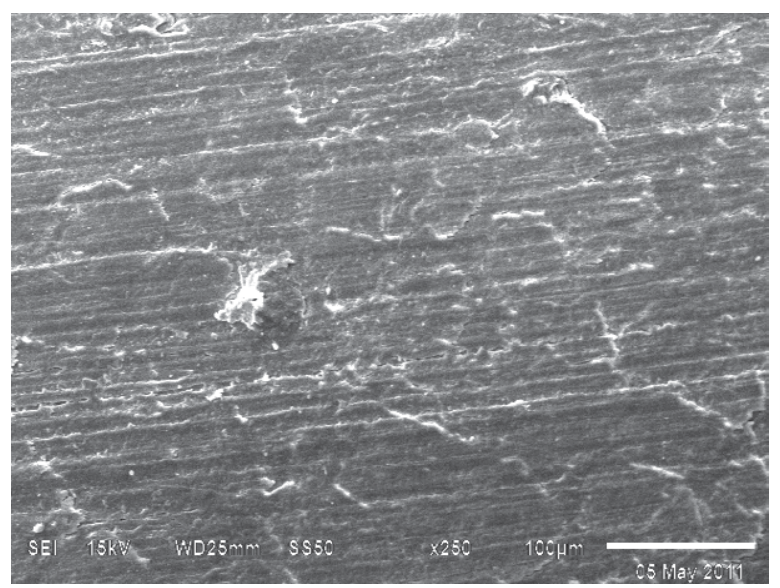

Figure 17: Nano rubber filled epoxy with glass fiber composite after wear.

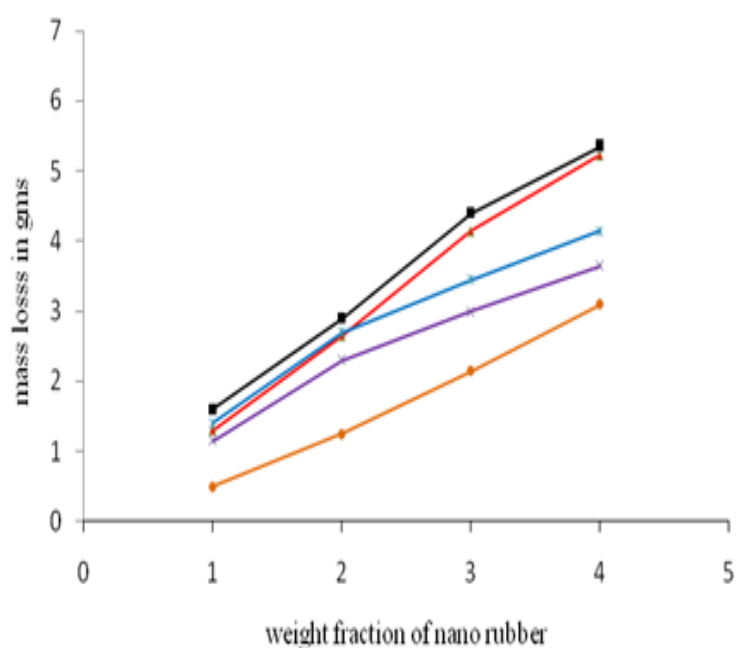

Figure 18: Weight fraction graph.

\section{Tensile strength}

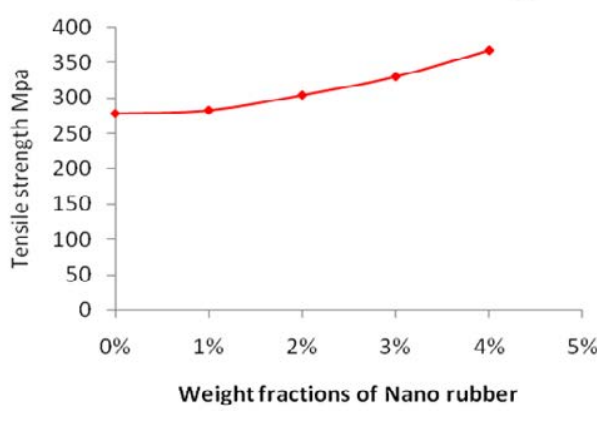

Figure 19: Tensile strength graph.

Flexural strength properties: I observed from below graph that the strength increases with the increase of the \% of nano rubber in composite material. This is due to nano rubber having high young's modulus. Hence it is proved that as the $\%$ of nano rubber increases. The strength also increases (Figure 21).
Flexural modulus properties: I observed from below graph that the stiffness decreases with the increase of the \% of nano rubber in composite material. This is due to nano rubber having high young's modulus. Hence it is proved that as the $\%$ of nano rubber increases. The stiffness decreases (Figure 22).

\section{Conclusion}

The enhancement of abrasive wear properties of epoxy glass fiber composites are carried out through the addition of nano nitrile butadiene rubber particles.

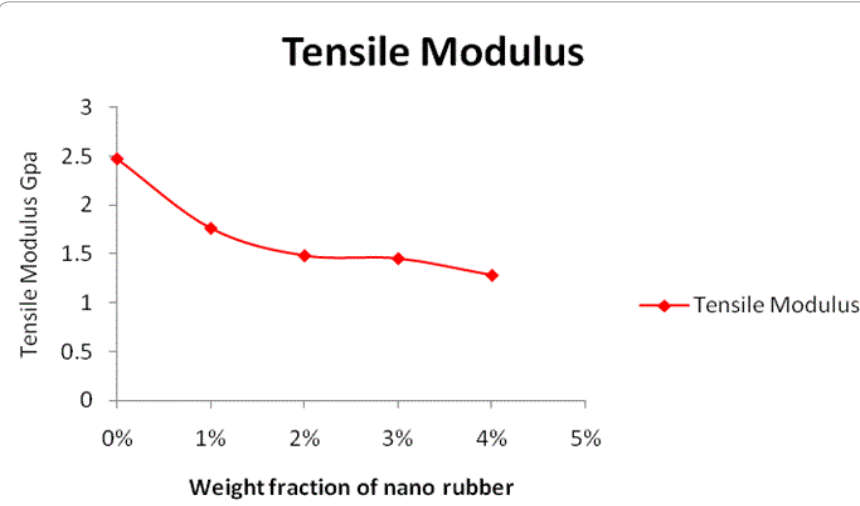

Figure 20: Tensile modulus vs weight fraction of Nano rubber.

\section{Flexural strength}

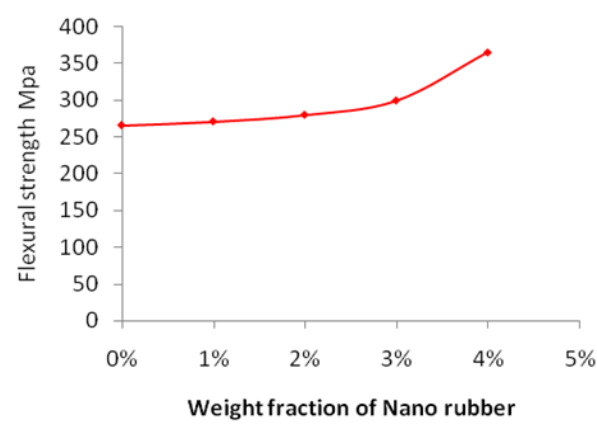

Figure 21: Flexural strength vs weight fractions of nano rubber.

\section{Flexural Modulus}

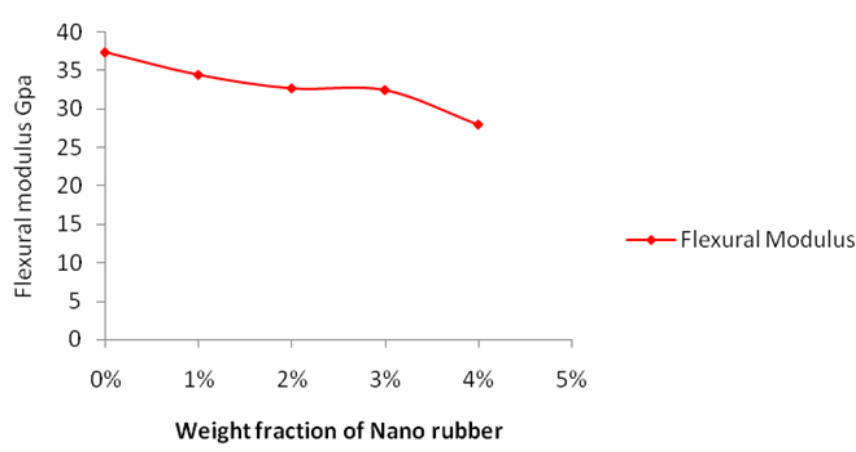

Figure 22: Flexural modulus vs weight fraction nano rubber. 
Citation: Srinivasarao D, Amareswari Reddy M, Krishna Veni MNV, Sandeep Kumar M (2014) Effect of Nano Rubber Additions on Wear and Mechanical Properties of Epoxy Glass Fibre Composites. J Material Sci Eng 3: 143. doi:10.4172/2169-0022.1000143

Page 8 of 8

Samples are fabricated with different weight fraction of nitrile butadiene rubber using hand layup technique. The morphology studies of nano nitrile butadiene rubber dispersion in epoxy glass fiber composite studied using Scanning Electron Microscope.

The experimental studies on associate properties like strength, stiffness are in tension and flexural is also carried out.

- The influence of weight fraction of nitrile butadiene rubber is on wear, tensile and flexural properties are carried out.

- Among the selected weight fractions $4 \%$ weight fraction is exhibited better wear, tensile and flexural properties are observed.

\section{References}

1. Advantages of Composites. Why Composites? Premix.

2. Dmitri Kopeliovich (2012) Classification of composites. SubsTech.

3. Thermosetting Composites - Fibres and Matrices. AZO Materials.
4. A/5. Thermoset Polymer Matrix Composites.

5. Merz EH, Claver GC, Baer M (1956) Studies on heterogeneous polymeric systems. Journal of Polymer Science 22: 325-341.

6. Bucknall CB, Smith RR (1965) Stress-whitening in high-impact polystyrenes. Polymer 6: 437-446.

7. Bucknall CB, Yoshii T (1978) Relationship between structure and mechanical properties in rubber-toughened epoxy resins. British Polymer Journal 10: 5359.

8. Newman S, Strella S (1965) Stress-strain behavior of rubber-reinforced glassy. Journal of Applied Polymer Science polymers 9: 2297-2310.

9. Advanced routes for polymer toughening. Kinloch, Shaw and Hunston and by Pearson and Yee.

10. Stickel JM, Nagarajan M (2012) Glass Fiber-Reinforced Composites: From Formulation to Application. International Journal of Applied Glass Science 3 : 122-136.

11. Collyer AA (2013) Rubber Toughened Engineering Plastics. Springer. 